\title{
A Business Process Modelling Approach to Improve OEM and Supplier Collaboration
}

\author{
Sara Mahdikhah, Mourad Messaadia, and David Baudry \\ CESI/IRISE, Rouen, France \\ Email: \{smahdikhah, mmessaadia, dbaudry\}@ cesi.fr \\ Richard Evans \\ University of Greenwich/School of Engineering, Greenwich, UK \\ Email: R.D.Evans@greenwich.ac.uk \\ Anne Louis \\ CESI/IRISE, Rouen, France \\ Email: alouis@cesi.fr
}

\begin{abstract}
Nowadays, Small and Medium sized Enterprises (SMEs) are facing fast changes in technological advancement. These changes encourage them to be more innovative and to offer their Original Equipment Manufacturers (OEMs) quality products with ever shorter deadlines, which is not an easy task. This project (BENEFITS) aims to provide innovative solutions to keep the most exploitable SME's skills within its local regions. This paper focuses on Business Process Modeling (BPM) and process interactions during the development phases of innovative products. Due to the specific needs and requirements in terms of Product Lifecycle Management (PLM)-based solutions for SMEs and OEMs, this work explores the relationship between them and their suppliers, based on ICT technologies and focuses on SMEs adoption of PLM. Such relationship needs the Business Process Modeling and Notation (BPMN) for representing all tasks that must be done for the collaborative process planning. Two existing information models (NIST and PPRO) serve as an information model to investigate the way of implementing design processes in the context of PLM.
\end{abstract}

Index Terms-Product Lifecycle Management (PLM), business process modeling, supply chain collaboration, SMEs/OEM, manufacturing.

\section{INTRODUCTION}

One of the major challenges in product development and lifecycle management is the time taken to market for new products. The objective of reducing the development cycle is not always achieved, for example, when Airbus announced delays to the A380 program in 2006. Also, in 2013, Toyota, Nissan, Honda and Mazda recalled more than 3.4 million cars, because of a potentially faulty passenger airbag. [1]

It has been identified that among the reasons for these failures, is the lack of coordination in the relationship between the OEM and its suppliers. This relationship is

Manuscript received October 14, 2013; revised January 23, 2014. characterized by the involvement of the supplier in the life cycle of the product until its integration into this cycle. This integration of suppliers in the value chain of the product is not a new challenge; many studies and projects have addressed this issue and seek to find the best way to achieve this integration. In this issue, research has been found works deal with aspects of interoperability [2], data exchange [3] and standards through the product life cycle [4], and those regards to organizational aspect between the OEM and its suppliers [5] through the development of various forms of cooperation with different degrees of integration. The goal is to advance suppliers to higher levels of autonomy and to win in a rank. According to project issue, we have the "ActionPlanT" project [6] which addressed a vision for "Manufacturing 2.0" based on the role of ICT for horizon 2020. The main objective of this vision is to illustrate that ICT still plays a major role in solving some of the most crucial pain points of European manufacturing.

The ICT adoption, especially those for collaboration, was driven by the expansion of the concept of cooperation and product management throughout its life cycle (PLM). Today, PLM approach becomes increasingly important in the strategies developed by companies. [8]

Also, the evolution of computer technologies, Computer Aided Design (CAD) and ICT tools, especially PLM tools helped the evolution of cooperation between OEMs and suppliers.

Thereby, the classic work has been a great evolution, like a few years ago in the automotive sector. [9] This evolution is characterized by the deployment of business networks between suppliers and OEMs. These networks are characterized by a "vertical cooperation" approach.[5] this cooperation resulted in the integration of equipment suppliers through simultaneous process of car development: in the planning / design and phases of education and achievement. 
The second section of this paper will focus on the PLM approach and its analysis according to different definitions. Section three will address collaboration aspects within extended enterprises, especially between suppliers (SMEs) and OEMs. In the fourth section, we focus on state of the art of collaborative design processes of extended enterprises into PLM systems; the work will use existing models as references. The last section will discuss a proposed BPMN workflow for conceptual design collaboration between SMEs and OEM. Finally, we will conclude and discuss future works according to BENEFITS project.

"BENEFITS" is a European project under the Program of INTERREG IVA France-Channel-UK. The project aims to keep SME's skills in France-Manche regions where they are trained. The main objectives of the project are to structuring a network of actors and integrating of SMEs/OEMs in to educational system which be adapted to both France and UK. Furthermore the project will provide SMEs/OEMs more efficient collaboration, better develop communication and higher security in exchanging data.

\section{PLM APPROACH}

PLM is a complex phenomenon in which several dimensions and disciplines use their contributions, [10]"bringing together products, services, structures, activities, processes, people, skills, application systems, data, information, methods, techniques, practices and standards. [11]

PLM is the act of bringing people together to accomplish common goals. Therefore, there are at least five questions that must be taken into account in the management of the life cycle of products: [12]

- When: the step where management occurs (related to Strategy / Process);

- Who: people, organisations involved in PLM (related to Organization)

- What: objects to manage in the PLM (related to Process)

- Why: challenges, motivations and objectives of PLM (related to Strategy)

- How to: the features and technologies that support PLM (related to Process/Tools)

In this project we analyse different PLM definitions according to researchers, conferences / Journals "Refs. [13] [14] [15] ", books "Refs. [13] [14] ", websites (PLM Interest Groups) "Refs. [13] [14] ", and especially industrial needs, such IBM and we see that there is a multitude of terms enclosed in this approach.

Beyond these terms listed in different definitions, we find a multitude of acronyms and other topics associated to PLM. The combination of all these terms/topics and acronyms is mainly due to the vast field that PLM is trying to cover. Today, PLM aims to address several concerns, via tools and resources often based on standards such as:

- Design Tools / Manufacturing / simulation of product data (CAD, document management etc.)
- Means of collaboration, management and sharing product data

- Standards and practices for the unification of data formats, languages, sharing and services

Following the various definitions and areas related to PLM, we noted that we could combine these terms along defined axes by grouping keywords and phrases according to their areas. Our initial analysis leads on drawing four pillars (levels) grouping terms often associated with PLM. These pillars are: the strategic level (Integrated Business approach, Portfolio Management, Virtual Enterprise), process level (Requirements Management, Change Management), the organisational level (collaborative mode, concurrent engineering) and finally, the tools implemented (ICT Architecture, product Structure).

\section{SMES COLLABORATION WITH EXTENDED ENTERPRISES}

Due to competition and globalisation, enterprises are supposed to work in networks and improve their performance through implementing optimal structure of information and communication technologies. In this way, despite the intent of SMEs to use those technologies, problems in structuring prohibit them in the exchange of information in a good manner. Benefiting from suitable modelling frameworks in the context of PLM will help them to reach this aim. In fact, PLM systems are supposed to develop management and the integration of information from the first conceptualisation to the disposal points. PLM systems are a solution to the better structuring and sharing of product information. OEMs and service providers need to implement a PLM system to integrate their information systems and processes through it. PLM has already been implemented in large companies, especially those within the aerospace and automotive sectors, but the cost, complexity and management of developing tools and combining PLM and CAD for small to medium enterprises, seems to be difficult "Fig. 1".

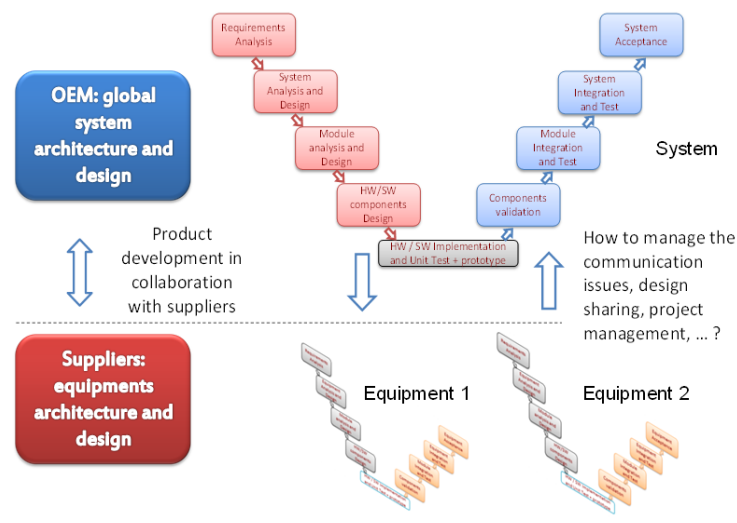

Figure 1. PLM and V cycle.

Today, design projects depend on the ability to coordinate and control the collaboration between the numerous actors participating in such projects.[18]

"Ref. [19]" identifies four major relationship types: 
- The vertical cooperation: This type of cooperation involves companies having or may have an OEM / supplier direct contract (transaction)

- The horizontal cooperation: this type of cooperation brings together competitors, engaged in a joint project

- The diagonal cooperation: this type of cooperation is between companies that have no direct transactions or competitive relationships, and whose products are complementary

- "Inter sectorial" cooperation: this type of cooperation is between companies from different sectors fully met the time of a project (we will not detail this type as it's not relevant in our study).

SME and OEM collaboration takes different levels described through a typology of different relationship patterns. According to the context of our project, we will detail the vertical cooperation mode.

\section{A. Vertical Cooperation}

Many OEM supplier networks in the automotive sector were developed in the 1980's. These networks are characterised by "vertical cooperation".

Vertical cooperation often begins with a relationship where the OEM requests the supplier to carry out the product production according to its precise specifications. The OEM keeps the industrial property of its product, liability and the product brand. We see that such cooperation can evolve to the level of co-development between OEM and suppliers.

In the automotive industry, the vertical partnership has resulted in the integration of equipment suppliers in a simultaneous development process of cars, in the planning / design and realisation.

Also in the aerospace industry, three kinds of vertical relationships (OEM/supplier) were developed [20]

- Classical relationship with OEM dominance (Boeing)

- Cooperative model (Airbus)

- OEM' $\mathrm{s}$ role is limited to the integration of purchased parts (OEM "architect": Bombardier).

TABLE I. VERTICAL COOPERATION LEVELS [21]

\begin{tabular}{|c|c|c|c|c|}
\hline \multicolumn{2}{|l|}{ Input data } & \multicolumn{3}{|c|}{ Activity/Supplier Level } \\
\hline \multicolumn{2}{|c|}{ Users Requirements } & \multicolumn{2}{|c|}{$\begin{array}{l}\text { Participate to elaborate } \\
\text { requirements, ..., manufacturing }\end{array}$} & 5 \\
\hline \multirow{2}{*}{$\begin{array}{l}\text { Functional } \\
\text { Requirements }\end{array}$} & \multirow{2}{*}{$\begin{array}{l}\text { Function } \\
\text { Component }\end{array}$} & \multicolumn{2}{|c|}{$\begin{array}{l}\text { Design, industrialization and } \\
\text { manufacturing }\end{array}$} & 4 \\
\hline & & \multicolumn{2}{|c|}{$\begin{array}{l}\text { Design, industrialization and } \\
\text { manufacturing }\end{array}$} & 3 \\
\hline \multirow{2}{*}{\multicolumn{2}{|c|}{ Specification }} & \multirow{2}{*}{$\begin{array}{l}\text { Participate to } \\
\text { the design }\end{array}$} & $\begin{array}{l}\text { Patent } \\
\text { registration } \\
(2 \mathrm{a})\end{array}$ & 2 \\
\hline & & & $\begin{array}{l}\text { Give up the IP } \\
(2 b)\end{array}$ & \\
\hline \multirow{2}{*}{$\begin{array}{l}\text { Product } \\
\text { Specification }\end{array}$} & \multirow[t]{2}{*}{ Technical } & \multicolumn{2}{|c|}{$\begin{array}{l}\text { Industrialization } \\
\text { manufacturing }\end{array}$} & 1 \\
\hline & & \multicolumn{2}{|c|}{ Manufacturing } & 0 \\
\hline
\end{tabular}

In vertical cooperation, there is a specific typology which represents the OEM/Suppliers relationship. It is based on two dimensions of supplier integration in the collaborative design process: the "degree of autonomy" of the supplier in the development of its component or subsystem and the "risk" attached to this integration towards the final project.[5] The authors identified five levels of autonomy (Table I).

These levels start from the lowest, level 0 and level 1, where the supplier is a contractor; they are responsible for product manufacturing and its industrialisation. Their work is especially based on the detailed technical specifications, (level 0: product, level 1: product and process specification).

In levels 2 and 3, the supplier is involved in the design through the plans and drawings from the OEM functional specifications (cost indications / expected performance, interface definition ...).

These two levels are similar; the key difference between these two levels is that in level 2, the OEM keeps the intellectual property rights on products developed and in level3, the supplier keeps the intellectual property of his developments, but provides the financial costs.

In level 4, the supplier is responsible for the design until the production of the component and this is on the basis of the functional specification.

In level 5, the supplier participates to the requirement analysis. An example of this kind of level is the collaboration during a project.

Managing the OEM/Supplier relationship aims to manage different levels of collaboration considering all of the chain:

- The strategic level defines the objectives of the relationship by asking questions about suppliers' competencies to associate, on their levels of integration in the project and the potential for collaboration between suppliers through networks, etc.

- The organisational level defines the shape of structure and collaboration modes that will achieve the strategic objectives.

- The operational level defines the processes that implement modes of collaboration and governing organisational structures.

- The system information level defines the functions of computer tools and their communication in order to ensure collaboration. This level also applies to all rules and procedures for the system's use.

\begin{tabular}{|c|c}
\hline PLM axes & \multicolumn{1}{c}{ Interoperability levels } \\
\hline Strategy & PLM Goals, organization mode \\
\hline Organization & Skills, Best practices, Ontology \\
\hline Process & $\begin{array}{l}\text { Standards, process synchronization, process models, } \\
\text { Ontology }\end{array}$ \\
\hline Iools & Implementation, Data models \\
\hline
\end{tabular}

Figure 2. Interoperability through PLM axes 
The implementation of such relationship requires establishing effective communication between different enterprises through interoperability mechanisms on several levels (Fig. 2).

\section{SATE of ART in Collaborative Design PROCESS OF EXTENDED ENTERPRISE IN TO PLM SYSTEM}

In this study, we investigated existing articles regarding collaborative design processes which have focused more on SMEs. By means of this research, we gathered all related information which allowed us to depict a BPMN model for representing all tasks that must be done for the collaborative process planning between extended enterprises, such as OEMs and SMEs. In addition, we have chosen two information models (NIST and PPRO) to show the effectiveness of these models for implementing design processes, especially in SMEs; the comparison has been shown in Table II.

Design coordination in the context of structure of the project is related to identify the local objective, assessment of resources, scheduling of the tasks and criteria. In SMEs, usually design coordination is narrated in macro-level and unfortunately it does not correspond to the complexity of the current process. "Ref. [19]" proposed a business approach for improving design coordination in SMEs through PLM system.

Process planning is an important step to converting a design concept to manufactured product. Nowadays, digital manufacturing systems are an important component of PLM and is one of the available solutions for managing integration Knowledge Information Data (KID) regarding to process. "Ref. [19] " proposed an ontology which formed the basis for developing decision support and knowledge management capability to increase the Computer Aided Process Planning (CAPP) solution.

Process planning activities have a critical role in manufacturing environments and collaborating different companies in product development is necessary. "Ref. [19] " proposed a work flow model for processes regarding collaborating planning with help of CAD, CAM tools \& PLM concepts. The target audience was OEMs and suppliers which interact with each other in different activists, different steps and information flows.

TABLE II. COMPARISON OF COLlaborative DESIGN PROCESS

\begin{tabular}{|c|c|c|c|c|c|c|c|}
\hline \multirow[t]{2}{*}{ Section } & \multirow[t]{2}{*}{ Task } & \multicolumn{4}{|c|}{ Articles } & \multicolumn{2}{|c|}{ Information model } \\
\hline & & C. Merlo & B. Denkena & H. R. Siller & M. Germani & NIST & PPRO \\
\hline \multirow{6}{*}{ Design } & Definition market Specification & ○ & & & & Specification & \\
\hline & Customer need design & O & & & & Requirement & \\
\hline & Analysais Drawing & O & & & & Feature & Import with CAD files \\
\hline & Implemention conceptual solution & ? & & & & Function & Product \\
\hline & Pre-testing protyping & & & & & Fuction model & Activity \\
\hline & Family product & & & & & Prpduct and compenant family & Version doucuments \\
\hline \multirow{3}{*}{$\begin{array}{c}\text { Manufacturing } \\
\text { Proposal }\end{array}$} & Meta Plan & & & & & Rationale & \\
\hline & Implicid $\mathrm{KID}$ report & & ○ & & & Master model & Product \\
\hline & Variable commercial data report & & 0 & & & & product \\
\hline \multirow{3}{*}{ Quotation } & Explicid KID report & & & & & & \\
\hline & Macro planning & & & & & Usage & Resource \\
\hline & Rough Micro plannig & & & & & Trace & Resource \\
\hline \multirow{6}{*}{ Planning } & Technologocal specification plan & & & & & OAM feature & Activity \\
\hline & physical prototype & & & & & Artifact & product \\
\hline & Experiment tests & & & & & Idealization & Activity \\
\hline & BOM Definition & & & & & Material & Producr(material) \\
\hline & Production planning & & & & & & Organization \\
\hline & Manufacturing scheduling & & & & & & \\
\hline \multirow{2}{*}{ Manufacturing } & Generate $\mathrm{CNC}$ code & & & & & & Organaziation \\
\hline & Manufacture & & & & & & Organaziation \\
\hline
\end{tabular}

Efficient collaborative product design is necessary for extended enterprises willing to develop complex products during a short time to market. "Ref. [19]" presented a method to define and evaluate a co-design platform regards to SMEs in the mechanical product field. System architecture is defined by applying proper metrics based on collaborative process characteristics to assess functionality performance of the available tools.
In the context of information modelling, the PPRO model is a framework which enables the manager to process technical data throughout the lifecycle management process applied in SMEs. This model includes four main packages of product, activity (process), resource and organisation and presents a configurable model covering all stages of the product life cycle management, Beginning Of Life (BOL), Middle of Life (MOL) and End 
Of Life (EOL). According to the object-oriented programming language, each attribute can be integrated at different levels of the life cycle in each section. In this research, PLM needs have been investigated in a company with regards to design and produces families.

The results demonstrate that their proposed models satisfy the needs in terms of PLM in this company. This approach deals with supporting several functionalities to develop and encounter the needs regarding PLM systems, such as knowledge capitalisation, reference management, archive management, quotation, reuse and the extension of fundamental knowledge for developing and industrialising the product in SMEs.

Since this model is dedicated to support requirements, problems and also benefits of the PLM-based solution for SMEs and OEMs, we chose it to make comparison. [22]

The NIST reference model is a single product interoperability framework which is able to assess, store, serve and reuse all the product information throughout the product's lifecycle and is proposed on the basis of National Institute of standards and Technology. The advantages of this framework are to include most of product information regarding the PLM system and its subordinate and to support interoperability among CAD, CAE, CAM and other interrelated systems. It provides a general repository of product information along its life cycle. This model is divided into four abstract models with general semantic: the Core Product Model (CPM), which provides a base-level product model; the Open Assembly Model (OAM) that is a standard representation for assembly and system-level tolerance information; the Design-Analysis Integration Model (DAIM) provides the technical basis for tighter design-analysis integration, and the Product Family Evolution Model (PFEM) which relates to the evolution of the product families. [23]

\section{PROPOSED BPMN WORKFLOW FOR CONCEPTUAL DESIGN COLLABORATION BETWEEN SMES AND OEM}

SMEs are mainly consisting of management groups who are owners of the company too. They usually have different activities with regard to the product development stages from technical feasibility to manufacturing and they work with other companies to develop new product or productive processes. In addition to overcoming particular needs faster, they need to adopt their design methods customised on specific product requirement. [24]

In this research we proposed a BPMN workflow model (Fig. 3) used for representing all tasks that must be carried out for the collaborative process planning between extended enterprises (OEM) and suppliers (SMEs) by means of exists relate articles. [24]-[27]

It is necessary to determine the different stages of lifecycle of process planning documents, which has been shown in the top ribbon of the BPMN model. This ribbon will help to track the document's history during the process planning activities. For this particular research, the stages established are: Design, Manufacturing Proposal, Quotation, Planning and Manufacturing. [27]
In the OEM part, the design team performs conceptual and detailed design after definition of marketing specification by customer marketing director. Definition of the customer needs design will start with the meeting of the marketing project manager and the customer. This person is responsible for evaluating the needs of the customer so he/she can reject directly the customer request, if the customer needs are not appropriated for the company (not formalised according to marketing specification). In this process if this meeting is enough to send the design detail to the designer, brief validation takes place; otherwise the designer must meet the customer alone or with the marketing representative to complete Customer Need Design (CND). At each task, the marketing representative or designer has the possibility to end the process when characterise the Customer Need Design document be clear. [25]

After the validation brief, analysis of drawings will be completed and CND document must figure conceptual implementing design and include engineering data, such as product geometry, product dimensions, tolerances, surface finish, additional manufacturing, processes, quality control requirements, media type, $\mathrm{CAD}$ type and packing instructions. [25] In continue Eng. Data document will send firstly to the director of Research and Development (R\&D) to implement the conceptual solution and secondly to the model maker for pre-test prototyping and validation of the designation to project management. [25]

After the creation of $3 \mathrm{D}$ modelling of the product, the model should be available in a shared data vault classified in a product family with a standard format. [27] In this level, the project manager will ask the purchasing department team, including industrial engineering, expert purchasing and $\mathrm{R} \& \mathrm{D}$ director in design department to review the manufacturability of the design and use the 3D model to create a manufacturing requirements file as feasibility reports. [27] [25]

This report must include implicit Knowledge Information and Data (KID), (customer prioritisation, contribution to reputation, previous experience with customer, customer flexibility, perceived risk, previous similar tasks, perceived future prospects) evaluating expert purchasing, variable commercial data (variable work costs, facility fixed costs, required profit margin, facility responsiveness, current backlog) evaluating industrial engineering and process plan at the meta-planning level (selection of technological processes, type of machines) by $\mathrm{R} \& \mathrm{D}$ in design department. Once the manufacturing process and feasibility report has been validated by the project manager, it will be available in a text document as a process planning file to suppliers, who will produce a manufacturing quotation. In order to produce a concise quotation, including costs and delivery time estimations, the technical department staff supplier must develop a macro plan and also a rough micro plan, containing set-ups, operations, sequence of operations, and tools to be used. [27] 


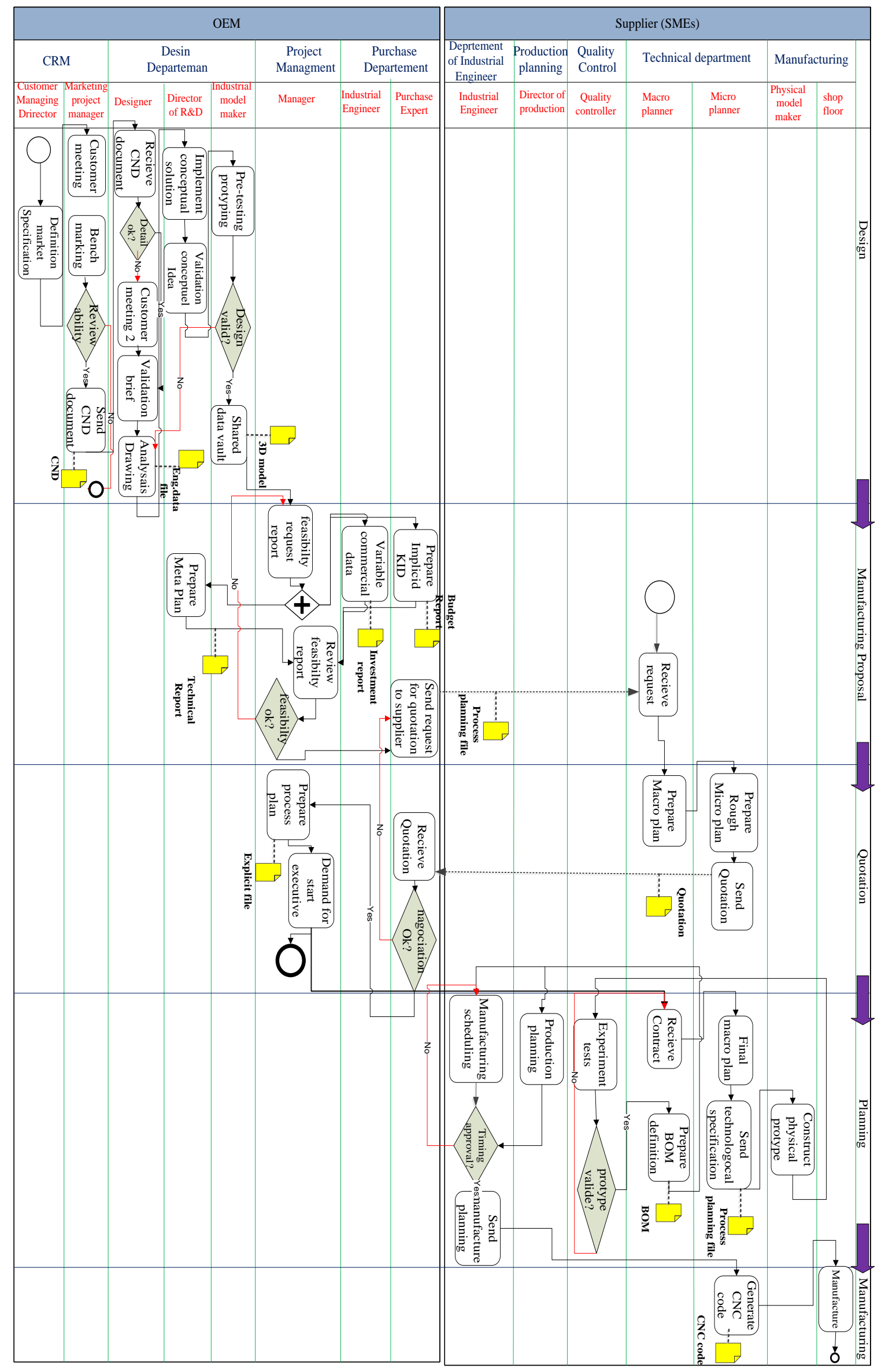

Figure 3. Proposed BPMN workflow for collaborative design process for extended enterprises 
Once the project manager of the SME has approved the quotation of the supplier, they will start to determine pre-process planning, including explicit facility KID (Process documentation, Resource templates, Process templates, available process standards, and CAD/CAM/CAPP tools). [25]

Following this, demand for start executive will be sent from the project manager to the technical department in the supplier organisation to undertake the final micro-plan (including tool paths), and it must be developed in a collaborative way with shop floor personnel. [27] [24]

This final macro plan will include the technological specification file and will be sent to the model maker in manufacturing to construct the physical prototype and it then continues to the department of quality control; the supplier will then do the experimental testing. [24]

If the prototype validation is confirmed, the technical department in the supplier company will prepare the Bill of Materials (BOM) definition. This BOM will be sent to the production director for determining production planning and secondly the industrial engineer for manufacturing scheduling. [24]

Finally, the production plan will be sent to the technical department to generate $\mathrm{CNN}$ code and then it will be sent to the shop floor for manufacturing. [24] [27]

At this point, the collaborative process planning for design will be finished and the related files, in supplier proprietary formats, will be saved in the repository's private area so that they can be retrieved for further process plans in case of similar parts. [27]

\section{CONCLUSION \& FUTURE WORK}

The introduction of new technologies (PLM) is a complex process that involves challenging the existing organisation, not only in terms of their information flow, but also the human resources management and OEM/Suppliers relationship level.

In order to model role-based views and finding interoperability between the various information and communication technology tools, a workflow BPMN model was presented. All tasks and steps have been developed according to existing research in the domain of design process applied collaboration in the extended enterprise and their supplier. In addition, two information models, namely NIST and PPRO, have been considered to investigate their related classes to the implementation design process in the context of PLM.

Future work should include further exploration into the details of the PLM approach, knowing that we are working on PLM roadmaps. We need to explore PLM adoption by SMEs and try to identify the main difficulties of suppliers in PLM adoption. Finally, such approach needs to be deployed to different PLM axes identified earlier (strategic, organisation, process, tools) and to identify key points allowing the PLM adoption.

\section{ACKNOWLEDGMENT}

We would like to thank Prof. James Gao, the head researcher team of the Center for Innovative Product Development of the University of Greenwich, for his remarks and collaboration on this work, and also Prof. Thierry Paquet and Prof. Bélahcène Mazari for their contributions.

Acknowledgement is made to European Union for the support of this research through the European Program INTERREG IVA France-Channel-UK by funding project entitled "Building an Expertise Network for an Efficient Innovation \& Training System (BENEFITS).

\section{REFERENCES}

[1] Toyota. Other Japanese automakers recall 3.4 million vehicles with Takata airbags. [Online]. Available: http://www.autonews.com/

[2] H. Panetto, G. Berio, K. Benali, N. Boudjlida, and M. Petit, "A unified enterprise modelling language for enhanced interoperability of enterprise models," in Proc. 11th IFAC Symposium on Information Control Problems in Manufacturing, INCOM'04, Salvador, Brazil, 2004

[3] Q. Xiao-li, Y. Hong, W. Xi-ying, and C. Ming-yuan, "Information shares of network manufacturing system based on STEP and XML," Journal of Computer Integrated Manufacturing System, vol. 8, no. 7, pp 293-316, 2002.

[4] L. Patil and R. D. Sriram, "Ontology formalization of product semantics for product lifecycle management," in Proc. ASME/IDETC CIE Conf, 2005.

[5] R. Calvi, M. Le Dain, S. Harbi, and V. Bonottoo, "How to manage early supplier involvement (ESI) into the new product development process (NPDP): Several lessons from a French study," in Proc. 10th International Annual IPSERA Conference, Jönköping, Sweden, 2001

[6] Actionplant. Factories for the future. [Online]. Available: http://www.actionplant-project.eu

[7] PLM interest Group. [Online]. Available: http://www.plmig.com/

[8] CIMdata. (2002). Product lifecycle management: Empowering the future of business. [Online]. Available: http://www.ariondata.com/servicios/documentacion/PLM_Definiti on_0210.pdf

[9] D. Tang and X. Qian, "Product lifecycle management for automotive development focusing on supplier integration," Computers in Industry, vol. 59, no. 2-3, pp. 288-295, 2008.

[10] S. Terzi, "Elements of product lifecycle management: Definitions, open issues and reference models," Ph.D. dissertation, Université Henri Poincaré Nancy I en Cotutelle Avec Politecnico di Milano, 2005 .

[11] J. J. Stark, "Product lifecycle management: Paradigm for 21st century product realisation," London: Spinger, 2004, pp. 562.

[12] W. Liu, Y. Zeng, M. Maletz, and D. Brisson, "Product lifecycle management: A review," in Proc. ASME, International Design Engineering Technical Conferences \& Computers and Information in Engineering Conference IDETC/CIE, August San Diego, USA, 2009.

[13] M. Abramovici and S. Schulte, "Study benefits of PLM - The potential benefits of product lifecycle management in the automotive industry," Chair of IT in Mechanical Engineering, Ruhr University Bochum, IBM BCS, Bochum, Frankfurt, 2004.

[14] M. Fathi et al., "Advanced condition monitoring services in product lifecycle management," in Proc. IEEE International Conference on Information Reuse and Integration, 2007.

[15] G. Schuh, H. Rozenfeld, D. Assmus, and E. Zancul, "Process oriented framework to support PLM implementation," Computers in Industry, vol. 59, pp. 210-218, 2008.

[16] D. Debeacker, "PLM, la gestion collaborative du cycle de vie des produits," Hermes Science Publications, May 1, 2004.

[17] A. Saaksvuori and A. Immonen, "Product lifecycle management," Springer-Verlag Berlin, May 2008.

[18] G. Pol, C. H. Merlo, J. Legardeur, and G. Jared, "Implementation of collaborative design processes in to PLM systems," Int. J. Product Lifecycle Management, vol. 3, no. 4, 2008. 
[19] J. S. Ben Mahmoud and R. Calvi. (2004). Intercompany cooperation in development projects. Chap 8. Doing research in project management. Paris. Vuibert Fnege. [Online]. pp. 161-188. Available:https://studies2.hec.fr/jahia/webdav/site/hec/shared/sites /jouini/acces_authentifie/Chapitres\%20dans\%20ouvrages\%20coll ectifs/Chapitre_8.pdf

[20] C. Alcouffe. (2001). Forms of business cooperation: the organization of R \& D in aeronautics and space. Report LIRHE Note $n^{\circ} 356, \quad C N R S / U T 1, \quad$ [Online]. Available: http://storage.canalblog.com/67/93/191146/7275471.pdf

[21] M. Messaadia, F. Belkadi, B. Eynard, and A. E. K. Sahraoui, "System engineering and PLM as an integrated approach for industry collaboration management," in Proc. INCOM, Romania, 2012.

[22] J. LeDuigou, A. Bernard, N. Perry, and J. Delplace, "Generic PLM system for SMEs: Application to an equipment manufacturer," International Journal of Product Lifecycle Management, vol. 6, pp. 51-64, 2012.

[23] R. Sudarsan, S. J. Fenves, R. D. Sriram, and F. Wang, "A product information modeling framework for product lifecycle management, " Computer-Aided Design, vol. 37, no. 13, pp. 1399-1411, 2005.

[24] M. Germani, M. Mengoni, and M. Peruzzini, "A QFD-based method to support SMEs in benchmarking co-design tools," Computers in Industry, vol. 63, pp. 12-29, 2012.

[25] G. Pol, C. H. Merlo, J. Legardeur, and G. Jared, "Implementation of collaborative design processes in to PLM systems," Int. J. Product Lifecycle Management, vol. 3, no. 4, 2008.

[26] B. Denkena, M. Shpitalni, P. Kowalski, G. Molcho, and Y. Zipori, "Knowledge management in process planning," Annals of the CIRP vol. 56, 2007.

[27] H. Siller, A. Estruch, and C. Vila, "Modeling workflow activities for collaborative process planning with product lifecycle management tools," J Intell Manuf, vol. 19, pp. 689-700, 2008.

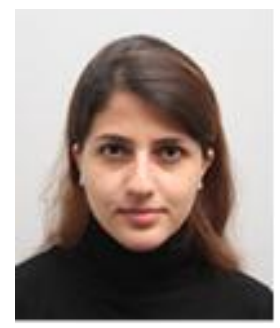

Sara A. Mahdikhah Was born in Tehran, Iran. She received her engineering diploma in industrial engineering from Mazandaran University of science and technology in Iran 2008 and then obtained her master of science in industrial engineering from University of Tehran, Iran 2010. She came to France and educated Master research in domain of "Knowledge Integration in Mechanical Production Design and Manufacturing" from Ecole National Supérieur d'Art et Métier (ENSAM Paris tech) in 2011. Now she is a PH.D fellow in industrial engineering and informatics from university of Rouen, France.

She actually works in IRISE laboratory located Graduate Engineering School CESI at Rouen.

Her topics of research are: Product life cycle management (PLM), Small and medium enterprises (SME), Information modeling, process modeling and collaboration between OEM and supplier.

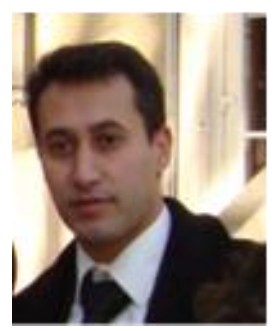

Mourad B. Messaadia was born in Constantine, Algeria, on 18 October 1972. He received the diploma of engineer in automation field on 1997 UBMA, Algeria. In 2003 he received his Master degree in Automation and production processes at Polytechnic National Institute of Grenoble (INPG). In 2008, he held a $\mathrm{PhD}$ degree in Industrial Engineering at LAAS-CNRS laboratory, University of Toulouse "Paul Sabatier".

He worked in Gas industry (GI) as a MAINTENANCE ENGINEER and also as WORKSHOP SUPERVISOR for three years. He worked as a RESEARCHER at the University of Technology of Compiegne (UTC) for five years. In 2013, he joined Graduate Engineering School CESI at Rouen as a LECTURER and RESEARCHER. He participated to European projects (ActionPlanT, Suplight and BENEFITS) and different
French projects.

Dr. Messaadia was also a reviewer of papers for IJPLM, IFAC, INCOM, and APMS and was member of research team at French System Engineering Association (Afis) and Eco-Design Systems for Sustainable Development (EcoSD). His current research interests are OEM-Supplier relationship, PLM approaches, system engineering and Eco-design.

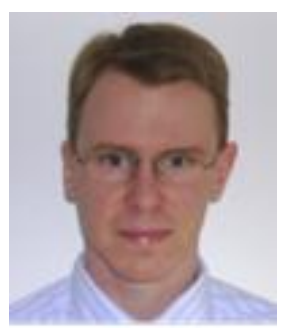

David C. Baudry was born in Paris, France, on August 14, 1974. He received an engineering diploma (equivalent to M. Sc.) from the Ecole Nationale Supérieure d'Ingénieur (ENSI) of Caen, France, in 1999 and a Ph.D in Electronics from the University of Rouen, France, in 2005

From 2000 to 2001 he joined SOPRA Group and was involved in software development. In 2001, he joined the Graduate Engineering School ESIGELEC at Rouen, France where he was lecturer and deputy head of the EMC Team of the ESIGELEC Research Institute (IRSEEM). He was also in charge of the "Mechatronic and electrical engineering" major in ESIGELEC. In 2010, he was entitled to supervise research. In 2011, he joined the Graduate Engineering School CESI at Rouen, France where he is currently lecturer and researcher.

His research interests include near-field EMC in electronic and mechatronic systems, electromagnetic simulations and modeling. He is actually involved in the development of the axes "Modelling and optimizing industrial performance" and "Technological tools for innovative products" of the IRISE laboratory

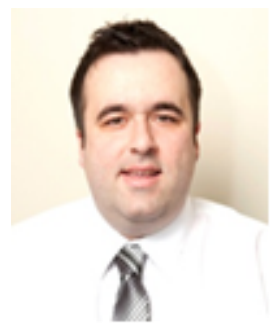

Richard D. Evans obtained his $\mathrm{PhD}$ from the University of Greenwich in 2013. He completed research into how Enterprise 2.0 Technologies could improve Collaboration and Knowledge Sharing in dispersed Product Development teams in the Aerospace and Defence Industry; the research was funded via an EPSRC Case Award in conjunction with BAE Systems' Electronic Systems sector, Rochester, United Kingdom. Previously, he had obtained an MSc in e-Commerce from the University of Wales in 2010 and a B.A. (Hons.) degree in Computing with Sports Science and Coaching from the University of Exeter, which was awarded in 2008.

He is currently a RESEARCH FELLOW within the Centre for Innovative Product Development and Manufacturing at the University of Greenwich, United Kingdom. Prior to starting his $\mathrm{PhD}$, he held the position of ONLINE PRODUCT MANAGER at Dunelm Mill plc, a FTSE 250 company, which is the largest home furnishings business in the UK. He is currently completing research in the field of "Knowledge Management in Collaborative Product Development" and is working on a European project in collaboration with CESi Association in Rouen, France and The University of Exeter.

Dr. Evans is a member of the Institution of Engineering and Technology, the Institution of Mechanical Engineers and the Chartered Institute of IT. He was also a Reviewer of papers for the IEEE International Conference on Teaching, Assessment and Learning for Engineering 2013

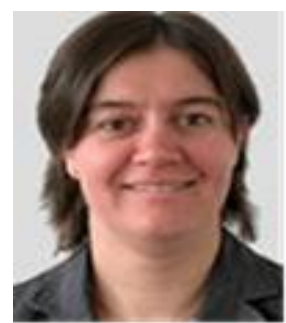

Anne E. Louis received her M.Sc. degree in Electronics, microwave and optical communications from the University of Limoges, Limoges, France, in 1994 and her Ph.D. in Microwave communications from IRCOM, University of Limoges, France in 1998

From 2003 to 2011, she has been the Head of the Electronics and Systems department of IRSEEM, ESIGELEC, Rouen, France. In 2006, she was entitled to supervise research and became Director of Doctoral Training at ESIGELEC in 2008. Since 2011, she is the Head of the CESI North-West team of IRISE laboratory. 